\title{
Variable Structural Networks at the Active Site of the SARS-CoV and
}

\section{SARS-CoV2 Main Proteases}

Navaneethakrishnan Krishnamoorthy ${ }^{1,2^{*}}$

${ }^{1}$ Systems Biology, Sidra Medicine, Doha, Qatar. ${ }^{2}$ National Heart and Lung Institute, Imperial College London, London, UK. *Correspondence: nkrishnamoorthy2@ sidra.org

\begin{abstract}
The novel coronavirus SARS-CoV2 (CoV2) emerged in December 2019. This virus has 88\% genomic similarity with SARS-CoV $(\mathrm{CoV})$, and both viruses largely depend on their main protease $\left(\mathrm{M}^{\text {pro }}\right)$ to regulate infection. $\mathrm{M}^{\text {pro }}$ thus represents an attractive target for anti-SARS drug design. The $\mathrm{CoV}$ and CoV2 $\mathrm{M}^{\text {pro }}$ are $97 \%$ identical at the sequence level, with 12 variable residues, and their X-ray structures appear similar. We thus structurally analysed how these variable residues affect the intra-molecular interactions between key residues in the CoV2 $\mathrm{M}^{\text {pro }}$ active-site. Compared to $\mathrm{CoV} \mathrm{M}^{\text {pro }}$, the 12 divergent residues in $\mathrm{CoV} 2 \mathrm{M}^{\text {pro }}$ exhibit modified intra-molecular interaction networks that ultimately restructure the molecular microenvironment. These altered networks also indirectly affect the networks of other active-site residues at the entrance (T26, M49 and Q192) and near the catalytic region (F140, H163, H164, M165 and H172) of the $\mathrm{M}^{\text {pro }}$. This suggest CoV2 indirectly (via neighbours) reshape key molecular networks around the $\mathrm{M}^{\text {pro }}$ active-site. It seems that the CoV2 $\mathrm{M}^{\text {pro }}$ deceives us with its apparent structurally identical to the $\mathrm{CoV} \mathrm{M}^{\text {pro }}$ while this viral system accumulates mass mutations (12 variable residues) at key positions. Some of these identified CoV2 $\mathrm{M}^{\text {pro }}$ networks at the active-site might guide design of efficient $\mathrm{CoV} 2 \mathrm{M}^{\text {pro }}$ inhibitors.
\end{abstract}

Keywords: COVID-19; SARS-CoV2; SARS-CoV; variable residues; main protease; structural analysis 


\section{Introduction}

In March 2020, the WHO declared that the outbreak of a novel coronavirus, SARS-CoV2 (CoV2), constituted a pandemic. This virus causes the transmissible disease, severe acute respiratory syndrome (SARS) $[1,2]$. Although the source of this virus is still unknown, CoV2 shares $88 \%$ genomic similarity with SARS-CoV (CoV) that was identified in $2003[3,4]$. CoV is highly dependent on the main protease ( $\mathrm{M}^{\text {pro }}$, or 3C-Like protease) for replicase polyprotein processing. By proteolytic cleavage, the $\mathrm{M}^{\text {pro }}$ generates functional ppla and pplb replicases in the host system that help to initiate and regulate infection [5]. $\mathrm{M}^{\text {pro }}$ is highly conserved among the coronaviruses, including $\mathrm{CoV} 2$; due to its essential role in the viral life cycle, it is considered as a major target for drug discovery [6-9]. Indeed, several studies have suggested that inhibitors of the $\mathrm{CoV} \mathrm{M}^{\text {pro }}$ active site might be repurposed to inhibit $\mathrm{CoV} 2 \mathrm{M}^{\text {pro }}$ [10-13].

The first X-ray structure of the $\mathrm{CoV} \mathrm{M}^{\text {pro }}$ was released with modified $\mathrm{N}$ and $\mathrm{C}$ terminals soon after the $2003 \mathrm{CoV}$ outbreak [7]. Years later, the authentic wild type structure of CoV $\mathrm{M}^{\text {pro }}$ (PDB ID: 2HOB. Fig. 1A) with an anti-coronavirus inhibitor (N3) was reported as a dimer (protomer $\mathrm{A}$ and protomer $\mathrm{B}$ ) and demonstrated the importance of the original $\mathrm{N}$ terminal, mainly residue S1 (protomer B) [14] for $\mathrm{M}^{\text {pro }}$ activity and inhibitor binding. The CoV $\mathrm{M}^{\text {pro }}$ has three functional domains I (1-101), II (102-184) and III (201-306) and a long loop (185-200) that connects domains I and II (Fig. 1 A-B). The catalytic residues H41 and C145 [15] are highly conserved among many of the SARS family proteins (MERS-M ${ }^{\text {pro }}$, HKU5-M ${ }^{\text {pro }}$, HKU4$\mathrm{M}^{\text {pro }}$ and SARS-M ${ }^{\text {pro }}$ ) [9] and they are also conserved in CoV2 $\mathrm{M}^{\mathrm{pro}}$. The substrate binding pockets including the active site (T25, T26, H41, M49, F140, N142, G143, S144, C145, H163, H164, M165, E166, P168, H172, Q189, T190, A191, Q192) are located in-between the cleft of domains I and II in the highly active wild type protease (PDB ID: 2HOB, [8,14]; these domains are rich in beta-sheets. The dimeric form is reported to be functional due to key interactions within and between the residues S1 (S1(B) from protomer B), F140, E166, H172 
and H163 (from protomer A) that serve to open and close the active site for ligand binding ([7,14,16-18]. Understanding the interactions between these functional residues in the new $\mathrm{CoV} 2 \mathrm{M}^{\text {pro }}$ is essential.

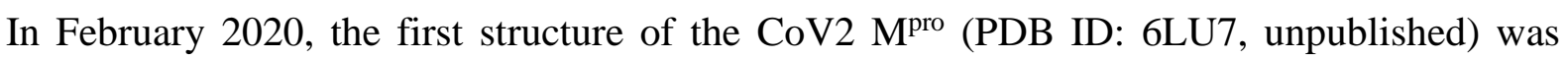
released. At high resolution, the $\mathrm{CoV} \mathrm{M}^{\text {pro }}$ and $\mathrm{CoV} 2 \mathrm{M}^{\text {pro }} \mathrm{X}$-ray structures look very similar with only a $0.5 \AA$ structural deviation (Fig. 1C). While sequence alignment between the two $\mathrm{M}^{\text {pro }}$ shows $97 \%$ identity (Fig. 1D), there are only 12 variable residues between them (Table 1). Furthermore, the two $\mathrm{M}^{\text {pro }}$ structures accommodate the same ligand (N3) differently (Fig. 1C). As molecular networks shape protein function, we analysed the impact of these 12 variable residues on their intra-molecular networks and subsequent functional relevance. Because functional studies are time consuming during this period of international emergency, we used a structural systems biology approach to initiate the dissection of these networks.

\section{Materials and Methods}

The high-resolution dimeric (protomer A and B) X-ray 3D structures of the CoV $\mathrm{M}^{\text {pro }}$ and the $\mathrm{CoV} 2 \mathrm{M}^{\text {pro }}$ were obtained from the protein data bank (PDB ID: 2HOB and 6LU7, respectively) to compare the equivalent structures. The structure of CoV2 $\mathrm{M}^{\text {pro }}$ was released by the same team [(Xue, (PDB, February 2020) unpublished] who released the highly active authentic wild type $\mathrm{CoV} \mathrm{M}^{\text {pro }}$ structure [14]. Pymol was used for structural analyses and to represent the molecular structures (www.pymol.org). Sequence alignment was carried out with Clustal Omega [19]. Dimplot in Ligplot with default parameters for hydrogen bonds and non-bonded interactions was used to analyse intra-molecular interactions [20]. 


\section{Results}

\section{The M $M^{\text {pro }}$ of CoV2 and CoV differ by 12 residues}

A parallel sequence alignment of the CoV2 $\mathrm{M}^{\text {pro }}$ and the CoV $\mathrm{M}^{\text {pro }}$ confirmed 12 variable residues at positions 35, 46, 65, 86, 88, 94, 134, 180, 202, 267, 285 and 286 (Fig. 1D and Table 1). The CoV2 $\mathrm{M}^{\text {pro }} \mathrm{X}$-ray structure of homodimer seemed to structurally mimic the CoV $\mathrm{M}^{\text {pro }}$ structure in terms of possessing similar domains and a comparable active site (Fig. 1 A-B). Most (8/12) of the variable residues were found in the $\mathrm{M}^{\text {pro }} \beta$-sheet-rich domains I and II, where the inhibitor/catalytic site is located; the remaining four residues were found in domain III. By contrast, the connecting loop possessed no variable residues.

Variable positions 46 and 65 are close to the bottle neck of the binding site (T25, T26, M49 and Q189), while variable positions 86, 88, 134 and 180 are close to the catalytic site. Variable position 134 also seems critical based on the detection of many functionally important residues [H172, E166, F140, S1 (B) and the oxyanion loop] in the vicinity. Notably, variable positions 46 and 134 are found in the loop that leads to the catalytic residues H41 and C145, respectively. These data suggest that despite overall structural similarity with the $\mathrm{CoV} \mathrm{M}^{\text {pro }}, 12$ divergent residues in the novel $\mathrm{CoV} 2 \mathrm{M}^{\text {pro }}$ might affect the activity of the cartalytic domain.

\section{The impact of the 12 variable CoV2 $M^{\text {pro }}$ residues on neighbouring residue interactions}

We next investigated the divergent interacting partners of the 12 variable residues. The interacting partners and/or interactions of the variable residues differed between the two proteases (Fig. 2 and Table 1). In CoV2 $\mathrm{M}^{\text {pro }}$, variable position 46 is located near the entrance of the binding site and shares the same loop with H41, however it is not interacting with M49 but this interaction is there in $\mathrm{CoV} \mathrm{M}^{\text {pro }}$. Variation at position 86 (near to the catalytic site) has a high impact on protease interactions, as this residue manages $10\left(\mathrm{CoV} 2 \mathrm{M}^{\mathrm{pro}}\right)$ and $12(\mathrm{CoV}$ $\mathrm{M}^{\mathrm{pro}}$ ) interactions with different partners (unique to CoV2 $\mathrm{M}^{\text {pro }}$ : E178 and CoV: L177, M162, 
H164). Variation at position 134 results in a change from a positively charged (H134) to a hydrophobic (F134) residue that ultimately expands the network of interacting partners in Cov2 $\mathrm{M}^{\text {pro }}$ (unique to F134: P108, F185).

The variable residues in domain III are located in the core region $(202,267)$ and likely have roles in the dimer formation (285 and 286). The residue at position 202 in the CoV $\mathrm{M}^{\text {pro }}$ has two unique partners, L250 and P293, and the total number of interactions decrease from nine in $\mathrm{CoV} \mathrm{M}^{\text {pro }}$ to seven in $\mathrm{CoV} 2 \mathrm{M}^{\text {pro }}$. The residue at position 267 is involved in $10\left(\mathrm{CoV} \mathrm{M}^{\text {pro }}\right)$ and $11\left(\mathrm{CoV} 2 \mathrm{M}^{\text {pro }}\right.$ ) interactions (unique to CoV: F219 and CoV2: E270 and L220). In the $\mathrm{CoV} 2 \mathrm{M}^{\text {pro }}$, the residue at position 286 makes new connections with T280 (protomer B) and G283 (protomer B), at the interface of the dimer.

Taken together, divergent interactions mediated by these 12 variable residues implies that they are networking differently in the $\mathrm{CoV} 2 \mathrm{M}^{\text {pro }}$ compared to $\mathrm{CoV} \mathrm{M}^{\text {pro }}$. The consequent changes in the nature of the amino acids (Table 1) at these variable positions might underlie these alterations to the interaction networks.

\section{The variable residues indirectly alter the interaction networks of the $M^{\text {pro }}$ active site}

To understand the consequences of the modified networks on the protease active sites, we compared the networks established by residues comprising the active site (including the entrance to the binding site region) between the CoV2 $\mathrm{M}^{\text {pro }}$ and $\mathrm{CoV} \mathrm{M}^{\text {pro }}$ (Table 2, Fig. 2 and Fig. S1). At the entrance, T26 changes its role with its partner T21 (from forming a hydrogen bond (in $\mathrm{CoV} \mathrm{M}^{\mathrm{pro}}$ ) to forming a hydrophobic interaction (in $\mathrm{CoV} 2 \mathrm{M}^{\mathrm{pro}}$ )). The $\mathrm{M} 49$ in $\mathrm{CoV}$ $\mathrm{M}^{\text {pro }}$, used P52 and A46 (variable residue) these interactions were not in CoV2 $\mathrm{M}^{\text {pro }}$. Residue Q192 at the entrance region forms two new hydrogen bonds with R188 and V186 as a result of the modified networks in CoV2 $\mathrm{M}^{\text {pro }}$. 
In the oxyanion loop, F140 is considered a functional regulator and (Xue et al., 2007); it forms hydrogen bonds with $\mathrm{S} 1$ (B) in $\mathrm{CoV} \mathrm{M}^{\text {pro }}$ and in CoV2 it makes a new link with S147. H163 interacts with $\mathrm{C} 145$ in $\mathrm{CoV} \mathrm{M}^{\text {pro }}$, but has lost a hydrogen bond with G146 in CoV2 $\mathrm{M}^{\text {pro }}$. The neighbouring residue $\mathrm{H} 164$ in $\mathrm{CoV} 2 \mathrm{M}^{\mathrm{pro}}$, has lost its interaction with L86 but gained an interaction with G174. M165 lies adjacent to the key residue E166 that is necessary to open the substrate binding site in $\mathrm{CoV} \mathrm{M}^{\text {pro }}[14]$. This residue shows two changes in interacting partners in CoV2 compared to CoV, losing D187 and R188 and gaining F181 and F185. E166 still makes its typical hydrogen bonds with $\mathrm{S} 1$ (B) and $\mathrm{H} 172$ in $\mathrm{CoV} 2 \mathrm{M}^{\text {pro }}$ as described in $\mathrm{CoV}$ $\mathrm{M}^{\text {pro }}$ [14]. In addition, we identified a hydrogen bond between H172 (as it is one of the essential regulators in the active site of $\mathrm{CoV} \mathrm{M}^{\text {pro }}$ ) and $\mathrm{S} 1(\mathrm{~B})$ in $\mathrm{CoV} 2 \mathrm{M}^{\text {pro }}$, which is not found in the $\mathrm{CoV} \mathrm{M}^{\text {pro }}$. Altogether, a few of the key active site networks are indirectly modified between $\mathrm{CoV} \mathrm{M}^{\mathrm{pro}}$ and $\mathrm{CoV} 2 \mathrm{M}^{\mathrm{pro}}$ as a result of direct changes to the neighbouring networks of the 12 variable residues.

\section{Discussion}

Our structural analysis of $\mathrm{CoV} 2 \mathrm{M}^{\text {pro }}$ highlights that this new viral system not directly altering any of the key residues E166, F140, H163, H172 and S1 (B) in the protease active site but rather changing the neighbouring residues to modify their micro-environment and their interaction networks (Table 2, Fig. 2 and Fig. S1). Why this indirect approach has been favoured to alter these key networks at the active site is unclear; it might be to preserve the original functional role of these residues (as observed in $\mathrm{CoV} \mathrm{M}^{\mathrm{pro}}$ ) while simultaneously modifying the way they function via their new networks. This concept now warrants detailed experimental analysis. The $97 \%$ identity between the $\mathrm{CoV} \mathrm{M}^{\text {pro }}$ and $\mathrm{CoV} 2 \mathrm{M}^{\text {pro }}$ shows a similar 
outlook; however, specific variations conferred by just 12 variable residues that modify interactions, especially in the protease's active site region, are clear at the 3D structural level.

The interactions made by residues in the oxyanion loop (140-145) stabilize the S1 pocket to control the conformational changes in their micro-environment that differ between the active and inactive forms of the $\mathrm{CoV} \mathrm{M}^{\text {pro }}[7,14,17]$. In $\mathrm{CoV} 2 \mathrm{M}^{\text {pro }}$, the residue at position 134 changes from being positive (H134) in $\mathrm{CoV} \mathrm{M}^{\text {pro }}$ to hydrophobic (F134); this change causes a modification to its network and it is located on the loop that lead to the oxyanion loop, that might ultimately serve to regulate the active site, as required. At the active site entrance, residues M49 and Q189 are essential gatekeepers for substrate binding [13,14]. While A46 interacts with M49 in $\mathrm{CoV} \mathrm{M}^{\text {pro }}$, this interaction is lost in $\mathrm{CoV} 2 \mathrm{M}^{\text {pro }}$ (S46) and thus might indirectly change the role of residues M49 and Q189. The other variable positions 86,88 and 180 are also located near to the catalytic site and their modified networks might similarly confer a potential change in their roles in $\operatorname{CoV} 2 \mathrm{M}^{\text {pro }}$. The networks produced by residues at the variable positions 285 and 286 in domain III are involved in dimer formation [18]. We now need to understand how the resulting altered networks in CoV2 $\mathrm{M}^{\text {pro }}$, especially around 286 (seven interactions in $\mathrm{CoV} \mathrm{M}^{\text {pro }}$ vs. ten in $\mathrm{CoV} 2 \mathrm{M}^{\text {pro }}$ ), impact the function of the protease.

Viral systems evolve rapidly at molecular level by mutations for their functional requirements during the process of natural selection $[21,22]$. Here, in both the $\mathrm{M}^{\mathrm{pro}} \mathrm{s}$, the catalytic residue H41 is sandwiched between variable positions 35 and 46 in the same super-secondary structure; these variable positions have both modified their nature from $\mathrm{CoV} \mathrm{M}^{\text {pro }}$ to $\mathrm{CoV} 2 \mathrm{M}^{\text {pro }}$ (polar to hydrophobic and hydrophobic to polar, respectively). H41 is conserved across all coronaviruses [9], thus there could be a functional reason or requirement behind a structural selection or modification near (but not at) this critical site. 
The X-ray structure of $\mathrm{CoV} \mathrm{M}^{\text {pro }}$ highlighted the role of residue S1 (from protomer $\mathrm{B}$ ) in stabilizing the active site by interacting with E166 (A) and F140 (A) and mediating inhibitor binding $[14,16]$. In CoV2 $\mathrm{M}^{\text {pro }}, \mathrm{S} 1$ (B) also seems to stabilize the active site, thus it is essential to consider a dimeric structure for ligand design. Interestingly, $\mathrm{S} 1$ (B) in CoV2 $\mathrm{M}^{\text {pro }}$ forms a unique hydrogen bond with H172: this new interaction might also contribute to its restructuring process. Going forward, the functional consequences of the 12 variable regions should be assessed at the conformational level and in terms of the regulation of protease activity. Functional assays, X-ray analyses like those performed previously [14] and molecular modelling approaches [17] are all warranted.

The CoV2 $\mathrm{M}^{\text {pro }}$ is one of the most targeted novel viral proteins for drug design following the recent outbreak of COVID 2019. However, in CoV2 $\mathrm{M}^{\text {pro }}$, the internal networks created by variable residues around the active site compared to well-known $\mathrm{CoV} \mathrm{M}^{\text {pro }}$ are not under the focus. This basic study shows their structural networks and thus can open up avenues of research in to developing effective targets for this novel virus. However, the functions of these new networks remain to be determined for insight into the mechanism of $\mathrm{CoV} 2 \mathrm{M}^{\text {pro }}$.

Conflict of Interest Statement: None to declare

\section{Acknowledgement}

The author would like to thank Dr. Damien Chaussabel, Director systems biology and immunology program at Sidra Medicine for his support and critical discussions. 


\section{Figure 1}
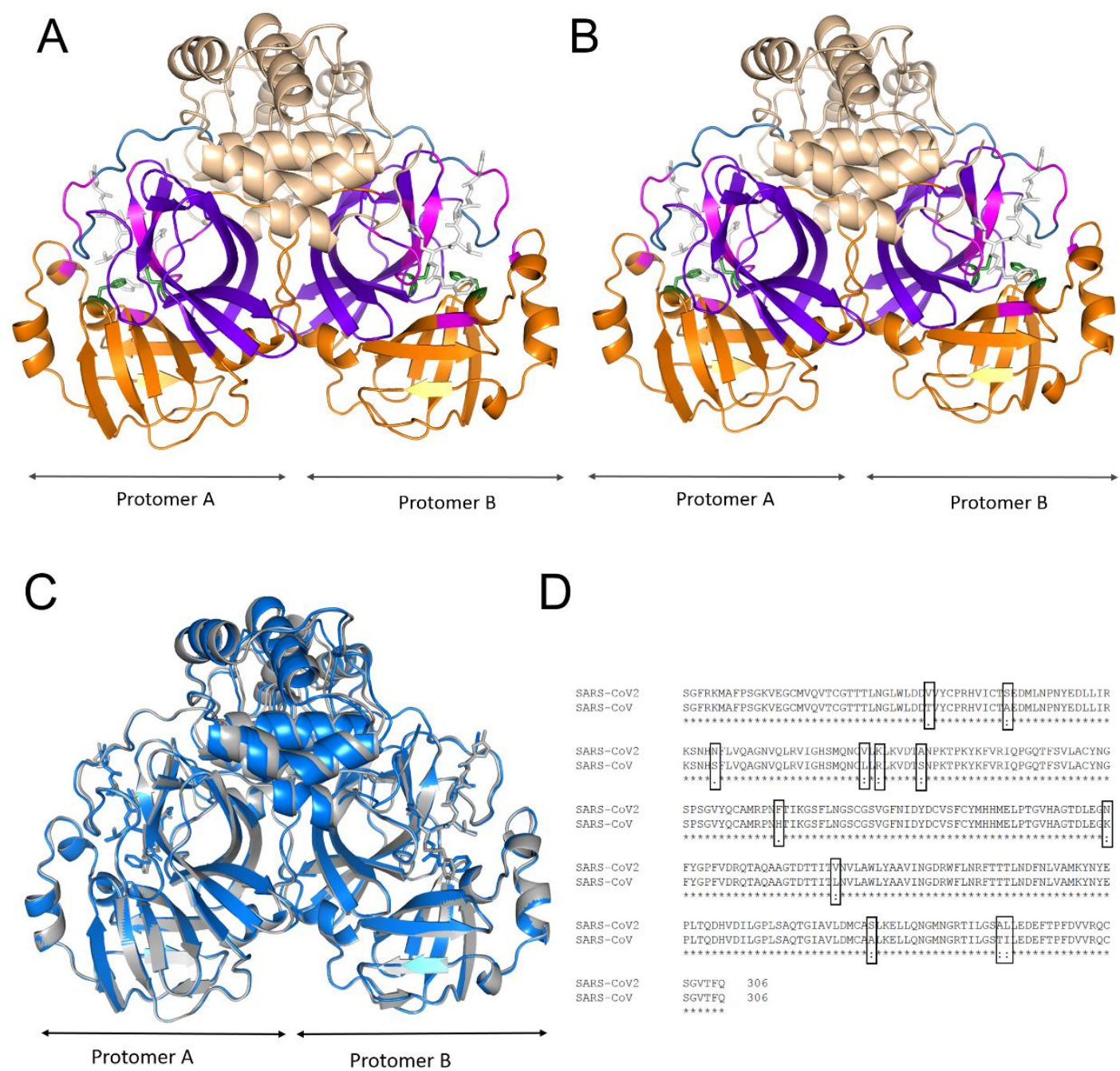

D
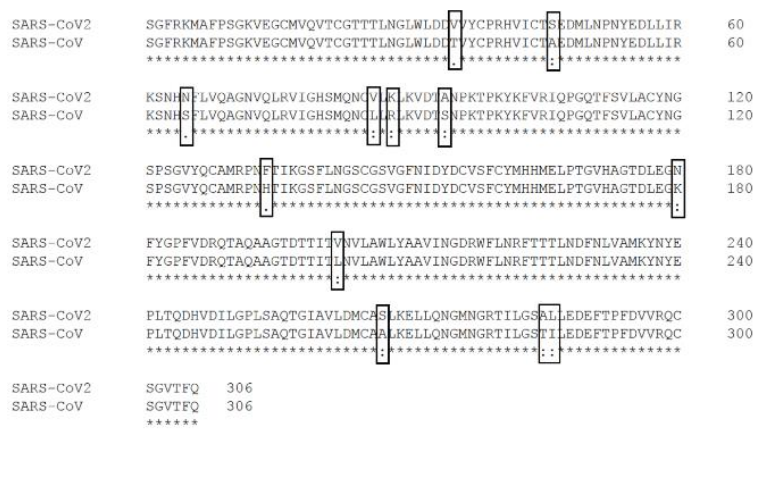

Figure 1. The X-ray structures and sequence alignment of the SARS-CoV $M^{\text {pro }}$ and

SARS-CoV2 Mpro. A) The dimeric structure of SARS-CoV M Mro $^{\text {pro }}$ (B) The dimeric structure of SARS-CoV2 $\mathrm{M}^{\text {pro }}$. (C) The overlapped structures of CoV $\mathrm{M}^{\text {pro }}$ (marine blue) and CoV2 $\mathrm{M}^{\text {pro }}$ (grey). The structures coloured as follows (in A\&B): orange: domain I (1-101), violet: domain II (102-184), wheat: domain III (201-306), sky blue: connecting loop (185-200), green sticks: catalytic residues $\mathrm{H} 41$ and $\mathrm{C} 145$, magenta: active site pocket and white sticks: inhibitor N3. (D) Multiple sequence alignment of the $\mathrm{CoV} \mathrm{M}^{\text {pro }} \mathrm{s}$, where $(*)$ indicates conserved residues and (. or :) shows 12 variable residues that are highlighted with black boxes. 


\section{Figure 2.}
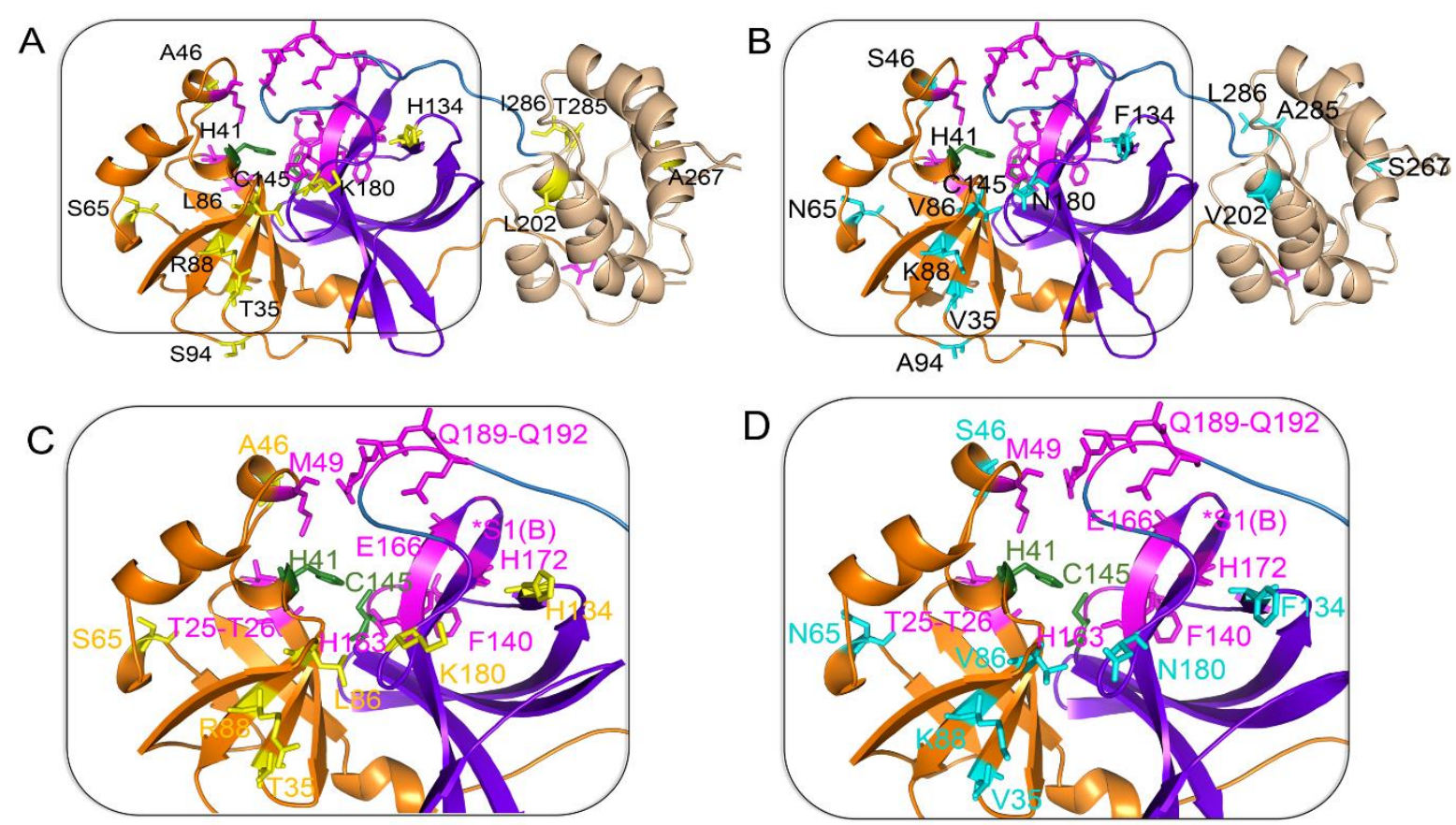

Figure 2: The variable positions and active site of the SARS-CoV Mpro and SARS-CoV2 $\mathbf{M}^{\text {pro. }}$ (A) The monomeric structure of SARS-CoV $\mathbf{M}^{\text {pro }}$. (B) The monomeric structure of SARS-CoV2 $\mathrm{M}^{\text {pro }}$. The boxed regions are magnified and showed in smooth-loop cartoons for clarity in (C) and (D) with colour-matched labels to indicate the positions of the key residues except S1 (protomer B) (removed for the clarity but indicated with symbol *S1(B)). Here, colour codes are: yellow sticks: unique residues in $\mathrm{CoV} \mathrm{M}^{\mathrm{pro}}$, cyan sticks: unique residues in CoV2 $\mathrm{M}^{\text {pro }}$, orange: domain I, violet: domain II, wheat: domain III, sky blue: connecting loop, green sticks: catalytic residues, and magenta sticks: active site residues. 


\section{References}

1. Huang C, Wang Y, Li X, Ren L, Zhao J, Hu Y, Zhang L, Fan G, Xu J, Gu X, et al. (2020) Clinical features of patients infected with 2019 novel coronavirus in Wuhan, China. The Lancet 395: 497-506

2. Zhu N, Zhang D, Wang W, Li X, Yang B, Song J, Zhao X, Huang B, Shi W, Lu R, et al. (2020) A Novel Coronavirus from Patients with Pneumonia in China, 2019. 382: 727-733

3. Ashour HM, Elkhatib WF, Rahman MM, Elshabrawy HA (2020) Insights into the Recent 2019 Novel Coronavirus (SARS-CoV-2) in Light of Past Human Coronavirus Outbreaks. Pathogens (Basel, Switzerland) 9:

4. Xu J, Zhao S, Teng T, Abdalla AE, Zhu W, Xie L, Wang Y, Guo X (2020) Systematic Comparison of Two Animal-to-Human Transmitted Human Coronaviruses: SARS-CoV-2 and SARS-CoV. Viruses 12:

5. Snijder EJ, Bredenbeek PJ, Dobbe JC, Thiel V, Ziebuhr J, Poon LL, Guan Y, Rozanov M, Spaan WJ, Gorbalenya AE (2003) Unique and conserved features of genome and proteome of SARS-coronavirus, an early split-off from the coronavirus group 2 lineage. Journal of molecular biology 331: 991-1004

6. Anand K, Ziebuhr J, Wadhwani P, Mesters JR, Hilgenfeld R (2003) Coronavirus main proteinase (3CLpro) structure: basis for design of anti-SARS drugs. Science (New York, N.Y.) 300: $1763-1767$

7. Yang H, Yang M, Ding Y, Liu Y, Lou Z, Zhou Z, Sun L, Mo L, Ye S, Pang H, et al. (2003) The crystal structures of severe acute respiratory syndrome virus main protease and its complex with an inhibitor. Proceedings of the National Academy of Sciences of the United States of America 100: 13190-13195 
8. Yang H, Xie W, Xue X, Yang K, Ma J, Liang W, Zhao Q, Zhou Z, Pei D, Ziebuhr J, et al. (2005) Design of wide-spectrum inhibitors targeting coronavirus main proteases. PLoS biology 3: e324

9. Tomar S, Johnston ML, St John SE, Osswald HL, Nyalapatla PR, Paul LN, Ghosh AK, Denison MR, Mesecar AD (2015) Ligand-induced Dimerization of Middle East Respiratory Syndrome (MERS) Coronavirus nsp5 Protease (3CLpro): IMPLICATIONS FOR nsp5 REGULATION AND THE DEVELOPMENT OF ANTIVIRALS. The Journal of biological chemistry 290: 19403-19422

10. Liu C, Zhou Q, Li Y, Garner LV, Watkins SP, Carter LJ, Smoot J, Gregg AC, Daniels AD, Jervey S, et al. (2020) Research and Development on Therapeutic Agents and Vaccines for COVID-19 and Related Human Coronavirus Diseases. ACS Central Science, 10.1021/acscentsci.0c00272

11. Chen Y, Yiu C, Wong K (2020) Prediction of the SARS-CoV-2 (2019-nCoV) 3C-like protease (3CLpro) structure: virtual screening reveals velpatasvir, ledipasvir, and other drug repurposing candidates [version 1; peer review: 2 approved]. 9:

12. Xu Z, Peng C, Shi Y, Zhu Z, Mu K, Wang X, Zhu W (2020) Nelfinavir was predicted to be a potential inhibitor of 2019-nCov main protease by an integrative approach combining homology modelling, molecular docking and binding free energy calculation. 10.1101/2020.01.27.921627 \%J bioRxiv2020.2001.2027.921627

13. Ton A-T, Gentile F, Hsing M, Ban F, Cherkasov A (2020) Rapid Identification of Potential Inhibitors of SARS-CoV-2 Main Protease by Deep Docking of 1.3 Billion Compounds. n/a: 14. Xue X, Yang H, Shen W, Zhao Q, Li J, Yang K, Chen C, Jin Y, Bartlam M, Rao Z (2007) Production of authentic SARS-CoV M(pro) with enhanced activity: application as a novel tagcleavage endopeptidase for protein overproduction. Journal of molecular biology 366: 965975 
15. Ziebuhr J, Snijder EJ, Gorbalenya AE (2000) Virus-encoded proteinases and proteolytic processing in the Nidovirales. The Journal of general virology 81: 853-879

16. Shi J, Sivaraman J, Song J (2008) Mechanism for controlling the dimer-monomer switch and coupling dimerization to catalysis of the severe acute respiratory syndrome coronavirus 3C-like protease. Journal of virology 82: 4620-4629

17. Tan J, Verschueren KH, Anand K, Shen J, Yang M, Xu Y, Rao Z, Bigalke J, Heisen B, Mesters JR, et al. (2005) pH-dependent conformational flexibility of the SARS-CoV main proteinase (M(pro)) dimer: molecular dynamics simulations and multiple X-ray structure analyses. Journal of molecular biology 354: 25-40

18. Lim L, Shi J, Mu Y, Song J (2014) Dynamically-driven enhancement of the catalytic machinery of the SARS 3C-like protease by the S284-T285-I286/A mutations on the extra domain. PloS one 9: e101941

19. Sievers F, Higgins DG (2014) Clustal Omega, accurate alignment of very large numbers of sequences. Methods in molecular biology (Clifton, N.J.) 1079: 105-116

20. Laskowski RA, Swindells MB (2011) LigPlot+: multiple ligand-protein interaction diagrams for drug discovery. Journal of chemical information and modeling 51: 2778-2786

21. Forni D, Cagliani R, Clerici M, Sironi M (2017) Molecular Evolution of Human Coronavirus Genomes. Trends in microbiology 25: 35-48

22. Dolan PT, Whitfield ZJ, Andino R (2018) Mechanisms and Concepts in RNA Virus Population Dynamics and Evolution. 5: 69-92 
Table 1. The networks of the 12 variable residues in the SARS-CoV Mpro and SARS-CoV2 Mpro

\begin{tabular}{|c|c|c|c|c|c|c|c|c|c|c|c|c|}
\hline $\begin{array}{l}\text { Variable } \\
\text { positions }\end{array}$ & $\begin{array}{l}\text { SARS- } \\
\text { CoV } \\
\text { Mpro } \\
\text { Residues }\end{array}$ & Nature & $\begin{array}{l}\text { No. of } \\
\text { HBs }\end{array}$ & $\begin{array}{l}\text { HBond } \\
\text { partners }\end{array}$ & $\begin{array}{l}\text { No. of } \\
\text { Hybs }\end{array}$ & Hydrophobic partners & $\begin{array}{l}\text { SARS- } \\
\text { CoV } \\
\text { Mpro } \\
\text { Residues }\end{array}$ & Nature & $\begin{array}{l}\text { No of } \\
\text { HBs }\end{array}$ & $\begin{array}{l}\text { HBond } \\
\text { partners }\end{array}$ & $\begin{array}{l}\text { No } \\
\text { of } \\
\text { Hybs }\end{array}$ & Hydrophobic partners \\
\hline $\mathrm{T} 35 \mathrm{~V}$ & $\mathrm{~T}$ & PU & 3 & L32, D34 & 5 & W31, V36, Y37, L89, D33 & V & $\mathrm{Hyb}$ & 2 & L32 & 6 & $\begin{array}{l}\text { W31, V36, D34, Y37, L89, } \\
\text { D33 }\end{array}$ \\
\hline A46S & A & Hyb & 0 & none & 4 & D48, E47, T45, M49 & $S$ & PU & 0 & none & 3 & E47, T45, E48 \\
\hline S65N & $S$ & PU & 2 & S62 & 5 & K61, F66, H64, C22, N63 & $\mathrm{N}$ & PU & 3 & S62 & 5 & C22, H64, F66, K61, N63 \\
\hline L86V & $\mathrm{L}$ & Hyb & 2 & Q83 & 10 & $\begin{array}{l}\text { C38, C85, L87, M82, } \\
\text { G179, L177, N84, M162, } \\
\text { H164, T175 }\end{array}$ & $\mathrm{V}$ & Hyb & 2 & Q83 & 8 & $\begin{array}{l}\text { C38, C85, L87, M82, G179, } \\
\text { N84, T175, E178 }\end{array}$ \\
\hline R88K & $\mathrm{R}$ & $(+)$ & 3 & S81, Q83 & 5 & L89, L87, V36, H80, K90 & K & $(+)$ & 2 & S81 & 7 & $\begin{array}{l}\text { V36, L87, L89, H80, Q83, } \\
\text { Y37, K90 }\end{array}$ \\
\hline S94A & $S$ & PU & 0 & none & 6 & $\begin{array}{l}\text { P96, N95, T93, D33, } \\
\text { W31, D34 }\end{array}$ & A & Hyb & 0 & none & 5 & P96, N95, T93, D33, W31 \\
\hline $\mathrm{H} 134 \mathrm{~F}$ & $\mathrm{H}$ & $(+)$ & 1 & R131 & 6 & $\begin{array}{l}\text { G183, N133, T135, } \\
\text { M130, P132, Y182 }\end{array}$ & $\mathrm{F}$ & Hyb & 1 & R131 & 8 & $\begin{array}{l}\text { G183, T135, N133, M130, } \\
\text { P108, P132, Y182, F185 }\end{array}$ \\
\hline K180N & K & $(+)$ & 3 & $\begin{array}{l}\text { R105, } \\
\text { D176 }\end{array}$ & 4 & G179, F181, T175, E178 & $\mathrm{N}$ & PU & 3 & $\begin{array}{l}\text { R105, } \\
\text { D176 }\end{array}$ & 5 & $\begin{array}{l}\text { G179, F181, T175, N84, } \\
\text { E178 }\end{array}$ \\
\hline L202V & $\mathrm{L}$ & Hyb & 1 & A206 & 8 & $\begin{array}{l}\text { L205, T201, N203, L250, } \\
\text { P293, I200, V204, H246 }\end{array}$ & $\mathrm{V}$ & Hyb & 1 & A206 & 6 & $\begin{array}{l}\text { I200, N203, T201, V204, } \\
\text { L205, H246 }\end{array}$ \\
\hline
\end{tabular}

doi:10.20944/preprints202003.0423.v1 


\begin{tabular}{|c|c|c|c|c|c|c|c|c|c|c|c|c|}
\hline A267S & A & $\mathrm{Hyb}$ & 3 & $\begin{array}{l}\text { L271, } \\
\text { E270, } \\
\text { D263 }\end{array}$ & 7 & $\begin{array}{l}\text { A266, L268, M264, F219, } \\
\text { N221, C265, K269 }\end{array}$ & $S$ & PU & 3 & $\begin{array}{l}\text { F219, } \\
\text { L271, } \\
\text { D263 }\end{array}$ & 8 & $\begin{array}{l}\text { A266, L268, M264, E270, } \\
\text { N221, L220, C265, K269 }\end{array}$ \\
\hline T285A & $\mathrm{T}$ & PU & 0 & & 5 & $\begin{array}{l}\text { T280, S284, I286, M276, } \\
\text { I286 (B) }\end{array}$ & A & Hyb & 0 & none & 5 & $\begin{array}{l}\text { S284, L286, M276, A285 } \\
\text { (B), L286 (B) }\end{array}$ \\
\hline I286L & I & Hyb & 2 & S284 & 5 & $\begin{array}{l}\text { W207, L287, T285, E288, } \\
\text { T285 (B) }\end{array}$ & $\mathrm{L}$ & Hyb & 2 & S284 & 8 & $\begin{array}{l}\text { M276, L287, A285, E288, } \\
\text { W207, T280 (B), G283 (B), } \\
\text { A285 (B) }\end{array}$ \\
\hline
\end{tabular}

Keys: HBs: hydrogen bonds, Hybs: hydrophobic interactions, Hyb: hydrophobic, PU: polar and un-charged, (+) positively charged and Bold fonts: variable partners or interactions in the corresponding network between CoV $\mathrm{M}^{\text {pro }}$ and $\mathrm{CoV} 2 \mathrm{M}^{\text {pro }}$. 
Table 2. The networks at the active site of the SARS-CoV Mpro and SARS-CoV2 Mpro

\begin{tabular}{|c|c|c|c|c|c|c|c|c|c|}
\hline \multicolumn{5}{|c|}{ SARS-CoV Mpro } & \multicolumn{5}{|c|}{ SARS-CoV2 Mpro } \\
\hline $\begin{array}{l}\text { SARS- } \\
\mathrm{CoV}\end{array}$ & $\begin{array}{l}\text { No } \\
\text { of } \\
\text { HBs }\end{array}$ & $\begin{array}{l}\mathrm{HB} \\
\text { partners }\end{array}$ & $\begin{array}{l}\text { No of } \\
\text { Hybs }\end{array}$ & Hydrophobic partners & $\begin{array}{l}\text { SARS- } \\
\text { CoV2 }\end{array}$ & $\begin{array}{l}\text { No } \\
\text { of } \\
\text { HBs }\end{array}$ & HB partners & $\begin{array}{l}\text { No } \\
\text { of } \\
\text { Hybs }\end{array}$ & Hydrophobic partners \\
\hline $\mathrm{T} 25$ & 3 & $\mathrm{C} 22, \mathrm{C} 44$ & 5 & $\mathrm{~T} 26, \mathrm{~T} 24, \mathrm{~T} 21, \mathrm{~V} 42, \mathrm{G} 23$ & T25 & 3 & $\mathrm{C} 22, \mathrm{C} 44$ & 5 & $\mathrm{~T} 26, \mathrm{~T} 24, \mathrm{~T} 21, \mathrm{~V} 42, \mathrm{G} 23$ \\
\hline T26 & 1 & T21 & 4 & Q19, T25, L27, V20 & T26 & 0 & & 5 & V20, L27, T25, Q19, T21 \\
\hline H41 & 1 & $\mathrm{C} 44$ & 8 & C145, V42, R40, P39, L27, Y54, I43, H164 & H41 & 1 & $\mathrm{C} 44$ & 8 & $\begin{array}{l}\text { C145, V42, R40, P39, L27, } \\
\text { Y54, I43, H164 }\end{array}$ \\
\hline M49 & 1 & Q189 & 8 & R188, D48, L50, P52, T45, A46, E47, N51 & M149 & 1 & Q189 & 6 & $\begin{array}{l}\text { R188, L50, D48, T45, E47, } \\
\text { N51 }\end{array}$ \\
\hline F140 & 2 & SER 1(B) & 8 & $\begin{array}{l}\text { H163, S139, L141, H172, S144, Y126, } \\
\text { Y118, V114 }\end{array}$ & F140 & 2 & SER 1(B) & 9 & $\begin{array}{l}\text { H163, S139, L141, H172, } \\
\text { S144, Y126, Y118, V114, } \\
\text { S147 }\end{array}$ \\
\hline N142 & 0 & & 4 & S144, G143, L141, Y118 & N142 & 0 & & 4 & S144, G143, L141, Y118 \\
\hline G143 & 1 & N28 & 5 & Y118, N142, S144, L141, C145 & G143 & 1 & N28 & 5 & $\begin{array}{l}\text { Y118, N142, S144, L141, } \\
\text { C145 }\end{array}$ \\
\hline S144 & 4 & S147, L141 & 8 & $\begin{array}{l}\text { Y118, C145, F140, G143, N28, C117, } \\
\text { N142, H163 }\end{array}$ & S144 & 4 & S147, L141 & 8 & $\begin{array}{l}\text { Y118, C145, F140, G143, } \\
\text { N28, C117, N142, H163 }\end{array}$ \\
\hline
\end{tabular}




\begin{tabular}{|c|c|c|c|c|c|c|c|c|c|}
\hline C145 & 3 & H164, N28 & 7 & G146, S144, H41, H163, L27, G143, S147 & C145 & 3 & H164, N28 & 7 & $\begin{array}{l}\text { G146, S144, H41, H163, } \\
\text { L27, G143, S147 }\end{array}$ \\
\hline H163 & 3 & $\begin{array}{l}\text { S147, Y161, } \\
\text { G146 }\end{array}$ & 8 & $\begin{array}{l}\text { H164, F140, M162, C145, M165, H172, } \\
\text { P39, S144 }\end{array}$ & H163 & 2 & Y161, S147 & 8 & $\begin{array}{l}\text { H164, F140, M162, C145, } \\
\text { M165, H172, P39, S144 }\end{array}$ \\
\hline $\mathrm{H} 164$ & 3 & $\begin{array}{l}\text { C145, } \\
\text { T175, A173 }\end{array}$ & 8 & $\begin{array}{l}\text { H163, M165, P39, L86, H41, C85, M162, } \\
\text { F181 }\end{array}$ & H164 & 3 & $\begin{array}{l}\text { C145, T175, } \\
\text { A173 }\end{array}$ & 8 & $\begin{array}{l}\text { H163, M165, P39, H41, } \\
\text { C85, M162, F181, G174 }\end{array}$ \\
\hline M165 & 2 & A173 & 7 & $\begin{array}{l}\text { H163, E166, H164, H172, V186, D187, } \\
\text { R188 }\end{array}$ & M165 & 2 & A173 & 7 & $\begin{array}{l}\text { H163, E166, H164, H172, } \\
\text { V186, F181, F185 }\end{array}$ \\
\hline E166 & 2 & $\begin{array}{l}\text { S } 1(B), \\
\text { H172 }\end{array}$ & 3 & M165, L167, V171 & E166 & 2 & S 1(B), H172 & 3 & M165, L167, V171 \\
\hline P168 & 0 & & 4 & G170, T169, L167, Q192 & P168 & 0 & & 4 & G170, T169, L167, Q192 \\
\hline H172 & 4 & $\begin{array}{l}\text { G138, I136, } \\
\text { E166 }\end{array}$ & 8 & $\begin{array}{l}\text { V171, F140, A173, T135, M165, H163, } \\
\text { G170, S1(B) }\end{array}$ & $\mathrm{H} 172$ & 5 & $\begin{array}{l}\text { G138, I136, } \\
\text { E166, S1(B) }\end{array}$ & 7 & $\begin{array}{l}\text { V171, F140, A173, T135, } \\
\text { M165, H163, G170, }\end{array}$ \\
\hline Q189 & 1 & M149 & 3 & L50, T190, R188 & Q189 & 1 & M149 & 3 & L50, T190, R188 \\
\hline $\mathrm{T} 190$ & 1 & R188 & 4 & Q192, Q189, A191, L50 & $\mathrm{T} 190$ & 1 & R188 & 4 & Q192, Q189, A191, L50 \\
\hline A191 & 0 & & 2 & T190, Q192 & A191 & 0 & & 2 & T190, Q192 \\
\hline Q192 & 0 & & 6 & V186, A193, A191, F185, T190, P168 & Q192 & 3 & R188, V186 & 5 & $\begin{array}{l}\text { A193, A191, F185, T190, } \\
\text { P168 }\end{array}$ \\
\hline
\end{tabular}

Keys: HBs: hydrogen bonds, Hybs: hydrophobic interactions, Hyb: hydrophobic and Bold fonts: variables partners or interactions in the

\footnotetext{
corresponding network between $\mathrm{CoV} \mathrm{M}^{\text {pro }}$ and $\mathrm{CoV} 2 \mathrm{M}^{\text {pro }}$
} 